\title{
marges Marges
}

revue d'art contemporain Revue d'art contemporain

05 | 2007

\section{L'exposition sous toutes ses formes}

\section{Éditorial}

Jérôme Glicenstein

\section{(2) OpenEdition}

Journals

Édition électronique

URL : http://journals.openedition.org/marges/686

DOI : 10.4000/marges.686

ISSN : 2416-8742

\section{Éditeur}

Presses universitaires de Vincennes

\section{Édition imprimée}

Date de publication : 15 juin 2007

Pagination : 2-5

ISBN : 978-2-84292-249-8

ISSN : 1767-7114

\section{Référence électronique}

Jérôme Glicenstein, « Éditorial », Marges [En ligne], 05 | 2007, mis en ligne le 15 juin 2008, consulté le 22 septembre 2020. URL : http://journals.openedition.org/marges/686 ; DOI : https://doi.org/10.4000/ marges.686

Ce document a été généré automatiquement le 22 septembre 2020

(c) Presses universitaires de Vincennes 


\title{
Éditorial
}

\author{
Jérôme Glicenstein
}

1 La question de l'exposition de même que la plupart des comptes rendus et l'intervention photographique d'Audrey Leblanc - traitent ainsi de l'exposition sous toutes ses formes. Il est vrai que cette question complexe est encore assez peu l'objet d'études poussées, bien qu'elle offre des clés indispensables à la compréhension de l'art contemporain.

2 Le premier article part du constat de la multiplication sans fin ces dernières années des biennales d'art contemporain. Jusqu'à présent ce phénomène n'était perçu que de manière assez anecdotique, suscitant tout au plus de vagues commentaires désabusés. Face à cette situation dont personne ne mesure véritablement l'étendue, l'intérêt de l'article d'In-Young Lim est d'avoir pris le problème à bras le corps en s'intéressant à l'ensemble des biennales créées ces quinze dernières années. Elle remarque au passage nombre de similitudes entre les différents événements ; similitudes qui touchent assez peu aux formes d'art présentées et bien plus aux échanges économiques internationaux ou aux politiques locales.

3 Autant cette étude pourrait être qualifiée de "macro-esthétique ", autant l'étude que consacre Caroline Chik à l'art interactif relève d'une "micro-esthétique ». Il ne s'agit pas dans son article de s'interroger sur les effets de la mondialisation sur la circulation de l'art, mais plutôt de voir ce qui, dans la poétique d'une œuvre, met en jeu une interaction entre le spectateur et le dispositif. Pour ce faire, elle s'appuie sur des œuvres utilisant la vidéo et les nouveaux médias. Il s'agit notamment de pointer la façon dont certaines situations "aménagent » une place singulière pour le spectateur. Tout en distinguant le modèle du « jouet » de celui du « jeu », elle cherche à retrouver certains « modèles » de relations dans les expériences du « pré-cinéma ».

4 L'article suivant interroge la relation entre les œuvres au sein des expositions. Bokyoung Lee analyse un certain nombre de projets présentés au cours de manifestations importantes ayant eu lieu ces dernières années ("Biennale de Lyon ", "Manifesta », «Printemps de septembre»). Elle pointe en particulier le fait que de nombreuses expositions refusent les espaces muséaux traditionnels et tentent d'envahir les espaces quotidiens. La question est alors posée des relations entre une programmation 
«internationale» ambitieuse et une insertion des propositions artistiques dans un «tissu local».

5 Emanuela Genesio a justement choisi de traiter un cas particulier de développement d'une politique culturelle locale: celui de la ville de Turin. Cette ville a en effet entrepris ces dernières années de développer son offre en matière d'art contemporain : à la Galerie d'art moderne (gam) et au Château de Rivoli se sont récemment ajoutées la Fondation Sandretto Re Rebaudengo, puis la Fondation Merz. Au-delà des prix, des expositions, des commandes publiques, des biennales et autres structures institutionnelles qui accompagnent ces créations, l'auteure s'interroge sur les motivations de la municipalité : s'agit-il de transformer le regard international sur Turin ou d'une opération à visée locale?

6 Le texte de Maxence Alcalde, plus historique, revient sur « Le "Primitivisme" dans l'art du 20 ${ }^{\mathrm{e}}$ siècle " (moma, 1984), "Les Magiciens de la terre » (Centre Pompidou / La Villette, 1989) et «Partage d'exotismes» («Biennale de Lyon», 1998). La présentation de la différence culturelle est-elle possible ? À quelles conditions ? Peut-on exposer des éléments issus de traditions extérieures à la nôtre ? Pour l'auteur, ces interrogations ne sont pas sans rappeler celles formulées - en d'autres circonstances - par Quatremère de Quincy.

7 Des questions du même ordre se retrouvent dans le texte de Monia Abdallah consacré aux expositions d'art en provenance du monde arabo-musulman en Occident. À quelles conditions peut-on parler d'un «art contemporain islamique "? S'agit-il de l'art contemporain occidental? Ou au contraire de formes inédites dont l'exposition n'a jamais été véritablement réussie en Occident? Les questions sociales, politiques ou économiques ne sont jamais totalement absentes de ce genre d'interrogation.

Le dernier texte est un entretien accordé par François Piron à Rozenn Canévet à propos de l'exposition «Subréel » qu'il avait organisée au mac de Marseille en 2002. Ses propos nous emmènent au cœur des discours de (et sur) l'art contemporain. Ce qui est à voir n'est semble-t-il jamais véritablement ce que l'on croit voir. Des choses sont à comprendre, mais il n'est pas sûr que leur sens soit directement accessible au visiteur. Les mots de François Piron peuvent paraître obscurs, voire élitistes; ils peuvent sans doute prêter à confusion. Mais c'est justement pour cette raison que nous avons choisi de les publier.

9 Un grand nombre de comptes rendus - particulièrement consacrés à des expositions - : "La Mélancolie ", "Labyrinthe invisible», «Dada», "John Maeda» et à des performances de Yann Duyvendak ou de Cause and Effect viennent compléter ce numéro. Deux recensions du même ouvrage: L'Élite artiste de Nathalie Heinich et le bilan $d u$ "Forum des revues universitaires en art» que nous avons organisé en novembre dernier complètent l'ensemble. 